depressed areas, holes or concavities present on the spore surface. $O L$-analysis is illustrated in Figs. 3 and 4. Around the spines (raised structures, hyaline in Fig. 3 and dark in Fig. 4) there are depressed areas (dark in Fig. 3 and hyaline in Fig.4) which, following pollen grain terminology, have been designated as 'lumina'. These cavities are bounded by 'muri' which are part of a reticulum enveloping the spore surface.

Erdtman ${ }^{1}$ credited $H$. Welcker as being the discoverer of this optical effect. In an ideal $L O$. analysis, all the raised structures in the upper focus should appear as bright dots against a black background. This is possible only if the spore surfaces are prrfectly flattened. In Figs. 1 and 3, because of the convex bulge in the spores, only a few spines are seen in such an ideal condition.

Perhaps, through $\mathrm{LO}$-analysis, some more unsuspected characters might come to light, as has happened in the case of urediospores of Scopella gentilis. Here the presence of lumina around the spines and of the reticulum around the urediospore surface was first inferred through $L O$-analysis. $L O$-analysis might even be important where paucity of spore material, for example, in aerobiology or in palæobotany, might not permit the use of other methods.

This work was performed while I held a research fellowship of the National Institute of Sciences of India to which due acknowledgment is made herewith. I am also grateful to Prof. S. P. Agharkar and Dr. M. J. Thirumalachar for encouragement and valuable suggestions.

Maharashtra Association for

\section{M. PAYAK*}

the Cultivation of Science,

Law College Building, Poona, India.

* Present address : Plant Pathological Station, Flowerdale, Simla E. 1 Erdtman, G., Svensk. bot. Tidskr., 50, 135 (1956)

\section{Lepidurus arcticus}

in the Irish Late-Glacial

THE recent discovery of a fine suite of Late-glacial strata near Ballyhalbert on the north-eastern Irish coast in an accessible position has allowed a careful study to be made of the different layers for plant and animal macrofossils. Particularly interesting has been the recovery of numerous characteristic telsons of the freshwater notostracan Lepidurus arcticus, a species which was reported recently by Mitchell $^{1}$ from Lateglacial levels at Ballaugh in the Isle of Man, at Neasham, Co. Durham, and at Mapastown, Co. Louth. Records from these Late-glacial contexts are significant since the species is not known in the present fauna of the British Isles. Its modern distribution is circumpolar, between $65^{\circ}$ and $80^{\circ} \mathrm{N}$.

At Ballyhalbert the telsons and mandibles occurred in great numbers in thin streaks of organic material which interrupted a solifluxion deposit of Zone III age. The deposit was a grey, sandy clay, packed with innumerable broken, angular fragments of slate. Within this the organic seams were lying horizontally. They yielded numerous leaves of Salix herbacea and also identified were Carex spp., Ranunculus sceleratus, Ranunculus (Batrachian) spp., Rumex tenuifolius, Viola palustris, Hippurus vulgaris, Menyanthes trifoliata, Lycopus europaeus, Selaginella selaginoides, and Chara spp. The large number of aquatics suggests that the organic seams had their origin as small pools. These perhaps formed each summer on top of the spring season's fresh sheets of solifluxion material.
The possibility may also be envisaged that the seams are really fragments of the underlying Alleröd or Zone II mud which could have been caught up and rolled into the solifluxion clay as it sludged into position. However, this seems an unlikely explanation since no remains of Lepidurus were discovered in the Zone II level. It was clearly restricted to the Zone III clay and did not appear above or below this horizon.

The absence of Lepidurus arcticus from the existing British and Irish faunas makes its widespread Lateglacial distribution all the more remarkable. Examples of such extinction and retraction of range during Post-glacial times are of course more familiar to us in plant kingdom, and Godwin ${ }^{2}$ has documented and discussed the problem in full. It is believed that the plants in question experienced curtailment of their range due to absorption of suitable habitats by the spread of the Post-glacial forests. But the factors responsible for the extinction of Lepidurus are otherwise and are difficult to envisage. Perhaps the problem may be approached constructively once quantitative and systematic studies on the sub-fossil micro-faunas of Late- and Post-glacial lake muds have accumulated to the extent of allowing the different factors in lake evolution $^{3}$ to be disentangled. Such studies are certainly to be commended since they may lead to a more accurate knowledge also of the duration and character of the important Post-glacial Climatic Optimum or Hypsithermal Interval.

Botany Department,

\section{E. S. MorrISON*}

The Queen's University, Belfast. May 4.

* Present address : Institut Botanique, Université de Montréal, 4101 est, rue Sherbrooke, Montreal 36, Canada.

1 Mitchell, G. F., Nature, 180, 513 (1957).

2 Godwin, H., "“'lhe History of the British Flora"' (Cambridge, 1956).

8 Deevey, E.'S., jun., Mem. Ist. Ital. Idrobiol., suppl. 8, 9-38 (1955).

\section{ENTOMOLOGY}

\section{Haematopota insidiatrix Austen (Diptera, Tabanidae) in Southern Rhodesia}

The fly-round technique has long been used in tsetse fly studies ${ }^{1}{ }^{2}$. The procedure is to walk along a pre-determined route collecting those flies attracted to men, to bait-animals or to screens carried by men. Recent work in the Wankie National Park, Southern Rhodesia, has shown that this method is also effective for the study of Haematopota insidiatrix Austen. This insect is frequently a nuisance at Wankie, during the rainy season (November-February), because of its habit of following and entering motorvehicles. It was because of this behaviour that the fly-round technique was tried as an aid to their study. A black cloth screen carried by two boys was found to be attractive to the flies. The use of a screen rather than a bait animal allows the technique to be standardized and also to be used in an essentially new way, namely, to study certain aspects of the sensory physiology of this insect.

Portchinsky ${ }^{3}$ noted that Haematopota pluvialis L. is attracted by black surfaces but that it avoids white ones. Curson ${ }^{4}$ states that Haematopota $\mathrm{sp}$. alighted on the black part of an animal's coat rather than the white part. In tsetse fly studies Swynnerton ${ }^{5}$ has stressed the usefulness of screens and Lloyd ${ }^{6}$ working with Glossina swynnertoni refers to a preference for 